\title{
Growth pattern in tropical mangrove trees of Bunaken National Park, North Sulawesi, Indonesia
}

\author{
RIGNOLDA DJAMALUDDIN \\ Department of Marine Science, Faculty of Fisheries and Marine Science, Universitas Sam Ratulangi. J1. Kampus Unsrat, Kleak-Bahu, Manado 95115, \\ North Sulawesi, Indonesia. Tel.: +62-431-868027, ${ }^{\bullet}$ email: rignolda@unsrat.ac.id; rignolda@gmail.com
}

Manuscript received: 2 March 2019. Revision accepted: 27 May 2019.

\begin{abstract}
Djamaluddin R. 2019. Growth pattern in tropical mangrove trees of Bunaken National Park, North Sulawesi, Indonesia. Biodiversitas 20: 1713-1720. Seasonal diameter growth patterns in mangrove are often related to rainfall, temperature and moisture regime. At any localities, specific environmental factors may influence growth rate of individual trees. I asked whether stem growth of tropical mangrove in BNP is constant over a year, and whether stem growth rates are different by sites, species, and trees of the same species. Dendrometer bands were installed on trees from twelve different sites in BNP to measure stem growth rates. Measurements were made at two months intervals from July 1999 to June 2001 and March 2014 to December 2016. Growth rates measured in trees at the twelve sites varied significantly from $0.83 \pm 0.27$ to $1.71 \pm 0.31 \mathrm{~mm}^{\text {month }}{ }^{-1}$. Growth rates were higher on Sonneratia alba $(1.65 \pm$

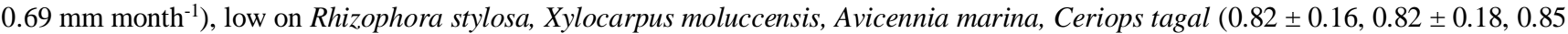
$\pm 0.18,0.88 \pm 0.28 \mathrm{~mm} \mathrm{month}^{-1}$, respectively), and medium on Rhizophora apiculata, Bruguiera parviflora, Bruguiera gymnorrhiza, Rhizophora mucronata $\left(1.19 \pm 0.16,1.22 \pm 0.69,1.25 \pm 0.49,1.31 \pm 0.22 \mathrm{~mm} \mathrm{month}^{-1}\right.$, respectively). Statistically, growth rates were higher in trees with initial girths more than $50 \mathrm{~cm}$ compared to trees with initial girth less than $50 \mathrm{~cm}$ on B. gymnorrhiza, C. tagal, and $R$. mucronata, but these were slower for $R$. apiculata and $S$. alba. Between individual trees in six species tested, the differences in diameter growth rate were statistically significant. Growth rates varied among different site conditions, and the effect of soil water salinity on these was significant at higher intertidal sites. Growth rates exhibited seasonal patterns, and these were correlated positively with rainfall and negatively with temperature. The effect of the 2015-2016 El Nino was significant on reduced growth rates.
\end{abstract}

Keywords: Dendrometer, El Nino, growth rate, tropical mangrove

\section{INTRODUCTION}

Mangrove is a relatively small group of higher plants which have been peculiarly successful in colonizing tropical and sub-tropical intertidal habitats at the interface between land and sea (Clough 1979; Duke 1992; Kathiresan and Bingham 2001; Maxwell 2015). Mangroves, which are tolerant to salt and brackish waters (Spalding et al. 1997), have developed complex morphological, anatomical, physiological, and molecular adaptations allowing survival and success in their highstress habitat (Srikanth et al. 2015). Despite all the ecological services and economic benefits associated with mangrove ecosystems, about $2.1 \%\left(2,834 \mathrm{~km}^{2}\right)$ of the existing worldwide mangrove area was estimated to be lost each year during the second half of the $20^{\text {th }}$ century (Valiela et al. 2001) and a total loss of $1.97 \%\left(1,646 \mathrm{~km}^{2}\right)$ from 2000 to 2012 (Hamilton and Casey 2016).

Mangroves in many tropical locales exhibit seasonal diameter growth patterns, often as a consequence of distinctive wet and dry seasons, and their seasonal patterns of growth are often related to rainfall, temperature, and relative moisture regimes (Krauss et al. 2006). Mangrove trees of the same species may show different growth rates due to specific environmental factors such as nutrients, salinity or inundation frequency of any localities (Suarez et al. 1998). According to Menezes et al. (2003), abiotic factors may influence the individual growth rates, but their effect on the forest structure is modified by biotic factors, such as neighborhood competition.

As in many tropical tree species, annual growth rings are commonly said to be absent in mangroves (Gill 1971; Tomlinson 1986), although these are claimed to be present in Rhizophora mucronata from the Kenyan coast (Verheyden et al. 2004). It is proposed by Robert et al. (2011) that the use of growth ring for age and growth rate determinations should be evaluated on a case by case basis. In the absence of annual growth rings, dendrochronological technique may not be applied, and that in this case, dendrometer band to measure increments in circumference growth offers an alternative to document fine-scale growth increments (Krauss et al. 2006). In practice, the growth rates of mangrove species may be a useful indicator of site conditions resulting from change (Krauss et al. 2006), key data of demographic processes to investigate the development of mangrove forests (Menezes et al. 2003), necessary for the establishment of sustainable silvicultural practices (Devoe and Cole 1998), important to generate a population model to determine cutting limits for harvesting of the mangrove trees (Rajkaran and Adams 2008), and a fundamental measurement to understand tree biology and physiology (Nazim et al. 2013).

The mangrove forests of Bunaken National Park (BNP) are among the most distinctive and unusual in Southeast Asia, because of the species that the forests contain and the ecological processes that are now taking place (Davie and 
Djamaluddin 1996; Djamaluddin 2004). It is believed that the interplay between geophysical, geomorphic and biological factors has supported the mangrove distribution and diversity in the intertidal environments of the Park. Previous study reported that there were at least 27 plant species distributed over ten habitat types (Djamaluddin 2018). A common dieback phenomenon associated with big trees of several species within the Park is also an important factor. While we do not know the lifespan of mangrove trees, this dieback is presumed to relate to old age. Long lifespan of mangroves in this area may be supported by their stable physical intertidal environments and the absence of catastrophic events (Djamaluddin 2004).

In this study, the growth dynamic of nine common encountered species in BNP was investigated. This study was designed to examine growth rates of trees growing at different conditions of intertidal environment over a period of 59 months, including the period of the 2015-2016 El Nino. This allowed for comparison of growth rates by sites with different conditions of tidal inundation and soil water salinity, by species from the same climatic zone and between the same trees species of large sizes and small sizes. In addition, seasonal pattern of growth rates was investigated using data of stem growth rates over several continuous wet and dry seasons, and growth dynamics in relation to rainfall and temperature were analyzed. This study was conducted to test the hypothesis that conditions of intertidal environments influence growth rates, and that distinct wet and dry seasons may have a consequence on seasonal pattern of growth rates.

\section{MATERIALS AND METHODS}

\section{Study site and climate}

The Bunaken National Park is situated on the North coast of Sulawesi Island. The Park consists of two sections, the northern section, and the southern section. The total area covered by the northern sections was 62,150 ha and the southern section was restricted to the mainland, covering a total area of 16,906 ha. Across the intertidal zone, the composition of mangrove species appeared to vary with types of sub-habitat. The seaward mangrove areas occupied mainly by species of Rhizophora ( $R$. apiculata, $R$. mucronata, $R$. stylosa) and $S$. alba. The middle mangrove areas were dominated by two species of $R$. apiculata and B. gymnorrhiza. The landward mangrove areas had a variety of sub-habitats, but mostly with dominant species of $C$. tagal. In the southern part of the Park where tidal channel components usually dissect the mangrove belt, the present of tidal stream edge was common, and this occupied mainly by species of $R$. apiculata, B. gymnorrhiza, A. marina, X. moluccensis (Djamaluddin 2018).

In this study, twelve sites in the southern section of the Park that were regarded as having different environmental conditions and community were selected (Figure 1). Attributes of each site are summarised in Table 1. These sites represented conditions at high intertidal environment including Site 1 (highly accreting inland fringe habitat; $01^{\circ} 22^{\prime} 00.50^{\prime \prime} \mathrm{N}, 124^{\circ} 33^{\prime} 18.84^{\prime \prime} \mathrm{E}$ ), Site 2 (less steep and eroding landward habitat; $01^{\circ} 22^{\prime} 01.53^{\prime \prime} \mathrm{N}, 124^{\circ} 33^{\prime} 16.09^{\prime \prime}$ E), Site 3 (less steep landward habitat; $01^{\circ} 22^{\prime} 05.50^{\prime \prime} \mathrm{N}$, $124^{\circ} 33^{\prime} 16.37^{\prime \prime} \mathrm{E}$ ), Site 11 (freshwater influenced habitat; $\left.01^{\circ} 19^{\prime} 43.85^{\prime \prime} \mathrm{N}, 124^{\circ} 31^{\prime} 14.14^{\prime \prime} \mathrm{E}\right)$; low intertidal environment or seaward fringe habitat including Site 4 $\left(01^{\circ} 22^{\prime} 24.37^{\prime \prime} \mathrm{N}, 124^{\circ} 33^{\prime} 10.31^{\prime \prime} \mathrm{E}\right)$, Site $5\left(01^{\circ} 22^{\prime} 20.01^{\prime \prime} \mathrm{N}\right.$, $124^{\circ} 33^{\prime} 04.72^{\prime \prime}$ E), and Site 7 (01 ${ }^{\circ} 22^{\prime} 13.57^{\prime \prime} \mathrm{N}$, $\left.124^{\circ} 32^{\prime} 58.41^{\prime \prime} \mathrm{E}\right)$; middle intertidal environment including Site $10\left(01^{\circ} 21^{\prime} 38.79^{\prime \prime} \mathrm{N}, 1^{\circ} 4^{\circ} 32^{\prime} 40.84^{\prime \prime} \mathrm{E}\right)$; tidal stream edge or river levee habitat including Site $6\left(01^{\circ} 22^{\prime} 21.08^{\prime \prime}\right.$ N, 124 33'09.00" E) and Site 8 (01 ${ }^{\circ} 22^{\prime} 07.20^{\prime \prime} \mathrm{N}$, $\left.124^{\circ} 33^{\prime} 04.20^{\prime \prime} \mathrm{E}\right)$; and transgressed bedrock coast habitat including Site $12\left(01^{\circ} 19^{\prime} 43.17^{\prime \prime}\right.$ N, 124³1'45.00" E).

The rainfall in the study area is strongly affected by wind systems (Djamaluddin 2004). The north-westerly winds blow over the South China Sea and bring moisture during September and April. In November, these winds arrive in the North Sulawesi via the Sulawesi Sea and to the west coast of South Sulawesi in late of November or early of December. Dry south-easterly winds blow from the wintery Australian land mass towards Eastern Sulawesi. These dry winds cause a short dry season in Manado from August to October. Based on data released by Manado Meteorology and Geo-physic Office, the total annual rainfall ranges from 2,501 to 3,000 $\mathrm{mm}$. During 1973 to 2016, the annual temperature of North Sulawesi varies little between $25.5^{\circ} \mathrm{C}$ and $27.0^{\circ} \mathrm{C}$. The minimum annual mean temperature of $25.5^{\circ} \mathrm{C}$ is recorded in 1984 and a maximum of $27.0^{\circ} \mathrm{C}$ in 2015 .

\section{Data collection}

Four canopy trees were selected from each of the twelve different sites to measure stem growth rate in the form of girth increment. The growth rates of selected trees were measured every two months during July 1999 to June 2001 and March 2014 to December 2016, using fixed dendrometer bands made with DYMO labeling tape produced by DYMO Esselte Pendaflex Corporation. These bands were attached around tree trunks using a spring and expand as the tree grows. The extent of girth expansion was measured on the tape using a micrometer.

Before the setting up of dendrometer in August 1999, data of structural attributes, soil water salinity, and tidal inundation were measured during July 1999. Structural attributes in the form of species composition and height of tree canopy were assessed to descript structural attributes of ecological mangrove communities at sample sites. Field determination of the flora was confirmed by a range of systematic reviews (e.g., Ding Hou 1958; Tomlinson 1986; Noor et al. 2006). The canopy height was measured directly by means of a long fixed stick for trees with height up to $5 \mathrm{~m}$ and, for taller trees, it was indirectly measured by using of a clinometer (SUNTO MC 1 Type). Surface soil sample was taken at 0 to $300 \mathrm{~mm}$ depth at five random points in every location, and soil water salinity was measured using a Hand-Held Refractometer (Atago Master-S/Mill) of water samples of a known volume eluted through sediment samples. Level of tidal inundation was observed at all sites during early neap-tide, full moon-tide, 
and late neap-tide. A pole gage was used to measure level of tidal inundation. Data of rainfall and temperature were based on the reports from Manado Meteorology and GeoPhysic Office.

\section{Data analysis}

In analyzing the differences in stem growth rate by species and sites, and the differences in stem growth rate by individual trees in each species, the one-way analysis of variance (ANOVA) was applied. Simple linear regression was used to analyze the effect of rainfall and temperature on stem growth rate.

\section{RESULTS AND DISCUSSION}

\section{Variation between sites}

Figure 2 shows the stem growth rates at different sites. The result from the ANOVA statistical test suggested that the differences in stem growth rate were significant between the twelve sites $(F(11,324)=5.848, p$-value $=$ $0.00,<0.05)$. The highest growth rates were found in trees at Site 5 and 7 where increments were $1.53 \pm 0.54$ and 1.71 $\pm 0.31 \mathrm{~mm}$ month $^{-1}$ respectively. Trees at Site 9 and 10 had average stem growth rates which were comparable, measured at $1.24 \pm 0.24$ and $1.20 \pm 0.53 \mathrm{~mm} \mathrm{month}^{-1}$ respectively. At Site 1 the average stem growth rates varied in the range of $1.01 \pm 0.30 \mathrm{~mm}$ month $^{-1}$. This range was slightly lower compared to that on sample trees at Site 4 of $1.05 \pm 0.15 \mathrm{~mm} \mathrm{month}^{-1}$, Site 6 of $1.07 \pm 0.19 \mathrm{~mm} \mathrm{month}^{-1}$, and Site 11 of $1.05 \pm 0.42 \mathrm{~mm} \mathrm{month}^{-1}$. Slightly lower stem growth rates were measured on trees at Site 3, 12, 2, and Site 8 of $0.83 \pm 0.27,0.84 \pm 0.25,0.90 \pm 0.39,0.92 \pm 0.31$ $\mathrm{mm}$ month $^{-1}$ respectively.

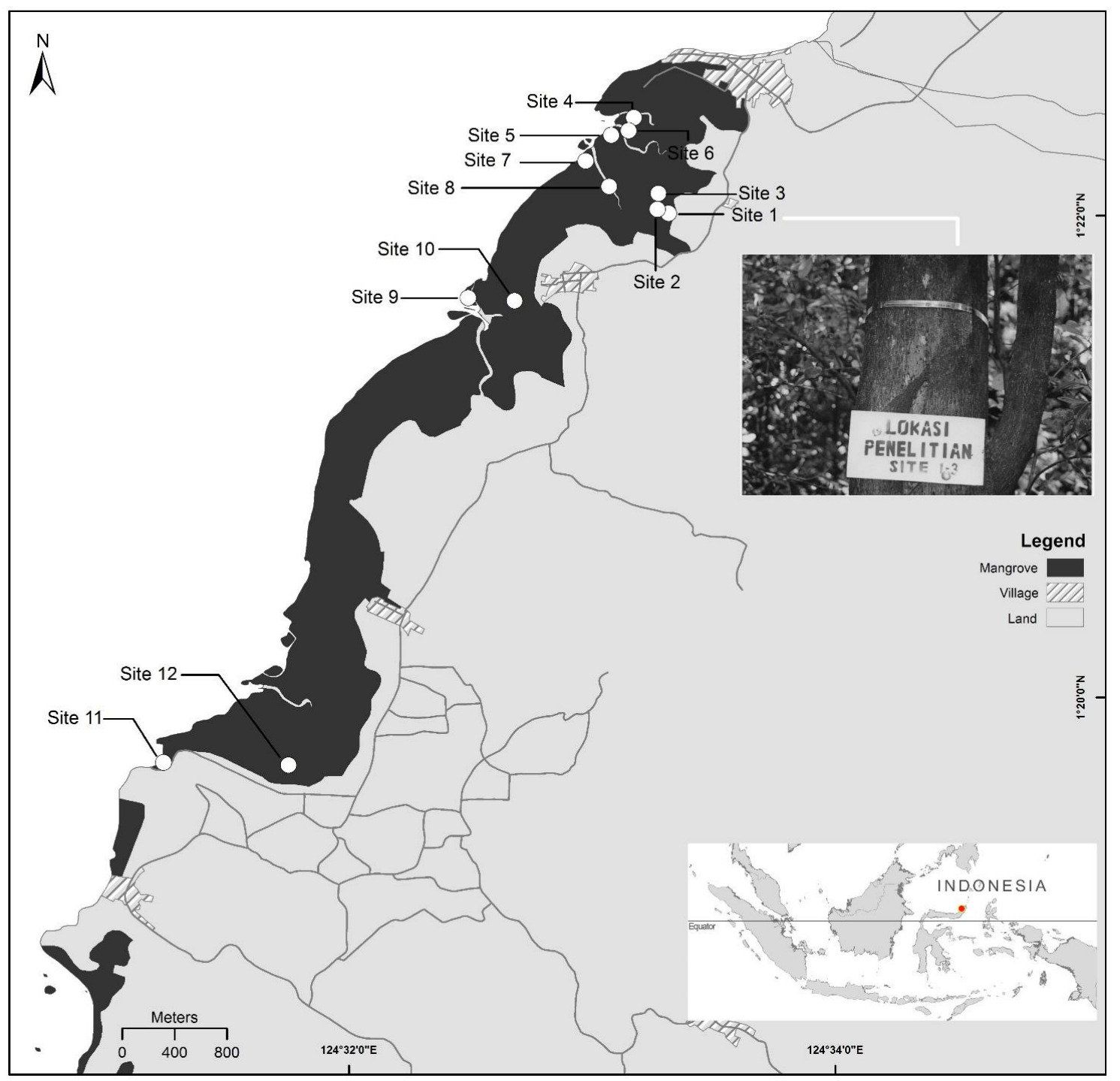

Figure 1. Map of study site with locations of the twelve sites sampled and a dendrometer on trees number 3 at Site 1 
Table 1. Description of the twelve sites sampled where four canopy trees in each site were selected for the measurement of stem growth rate: SD (Standard Deviation) of five random soil samples, tidal inundation frequency represented number of day month ${ }^{-1}$ a site being inundated by seawater

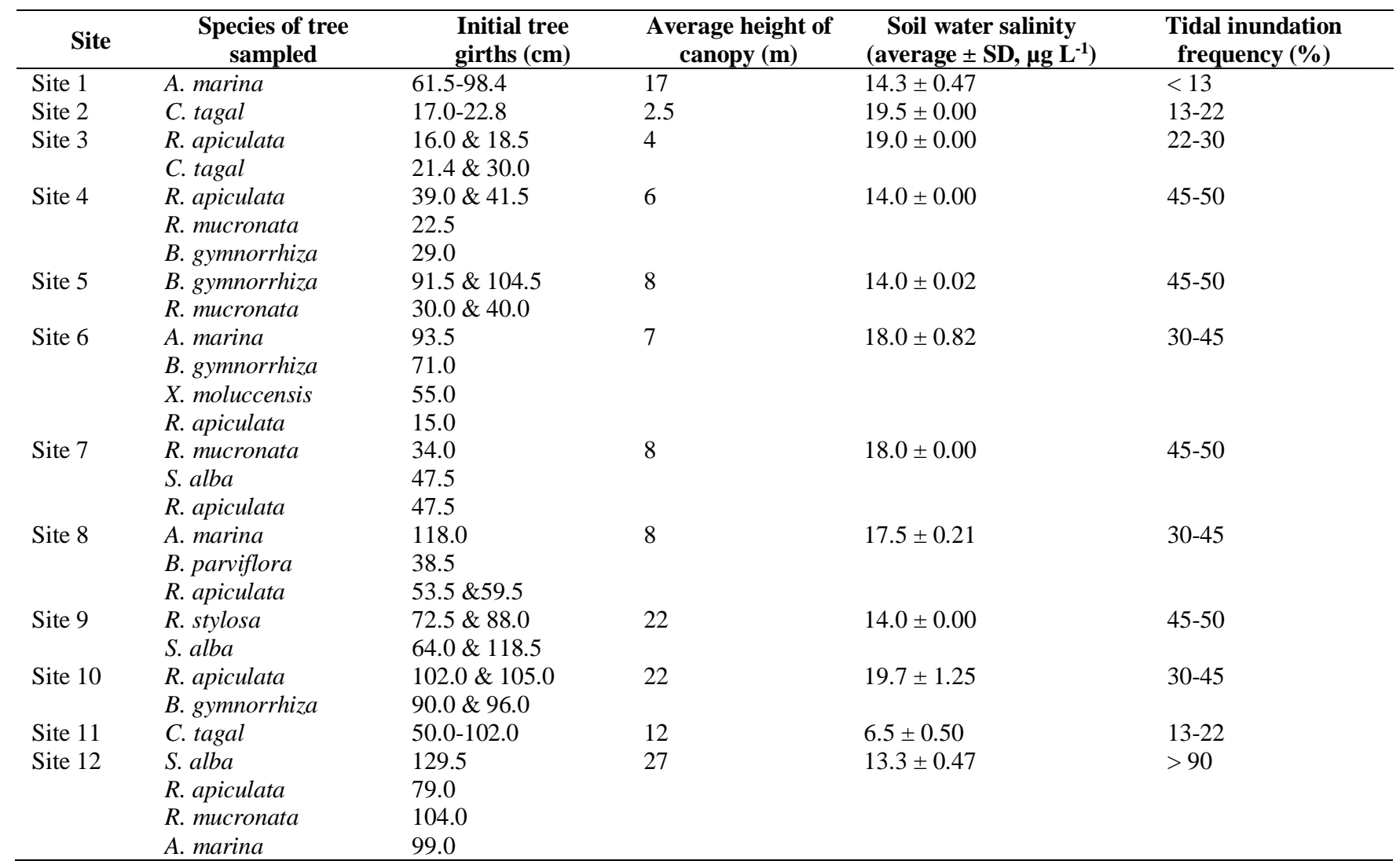

Differing conditions at the study sites resulted in different growth rates of mangrove species. Results from this study indicate that higher growth rates were measured at Site 5 and 7 (low intertidal environment) where soil water salinity was at intermediate level $\left(14.0 \pm 0.02 \mu \mathrm{g} \mathrm{L}^{-1}\right.$ and $18.0 \pm 0.00 \mu \mathrm{g} \mathrm{L}^{-1}$, respectively), and a relatively lower growth rate was recorded for trees growing at Site 2 and 3 (high intertidal environment) where soil water salinity was relatively higher $\left(19.5 \pm 0.00 \mu \mathrm{g} \mathrm{L}^{-1}\right.$ and $19.0 \pm 0.00 \mu \mathrm{g} \mathrm{L} \mathrm{L}^{-1}$, respectively). The effect of soil water salinity on growth rate might be inconsistent considering a relatively lower growth rate at Site 8 and 12 where soil water salinity was at intermediate level $\left(17.5 \pm 0.21\right.$ and $\left.13.3 \pm 0.47 \mu \mathrm{g} \mathrm{L}^{-1}\right)$. This inconsistency was probably due to the existence of micro-topography in form of the river levee at Site 8 and transgressed bedrock coast at Site 12. These microtopography variations according to Thom (1982) can cause varying physiological responses in different species and there may be more or less favorable plant growth in a specific habitat due to the response of species to stress conditions.

Although soil water salinity was relatively higher (19.7 $\pm 1.25 \mu \mathrm{g} \mathrm{L}^{-1}$ ) at Site 10 , growth rates of trees at this site were measured at medium growth rate. This rate of growth was probably affected by tidal inundation frequency of this site that was measured at 30 to $45 \%$ compared to 13 to $30 \%$ at Site 2 and 3. How trees of B. gymnorrhiza and $R$. apiculata respond to specific conditions at Site 10 needs further investigation. The effect of salinity on mangrove growth has been reported by various studies (e.g. Robert et al. 2009; Menezes et al. 2003; Nazim et al. 2013; Noor et al. 2015). In Pakistan, for example, Nazim et al. (2013) reported that the maximum growth rate of A. marina was presumably due to low salinity and the minimum growth rate was related to higher salinity. Similar pattern was reported by Menezes et al. (2003) in the mangroves from Braganca Peninsula, North Brazil. In mangrove forests, conditions of high salinity can cause osmotic stress and reduce the availability of water, resulting in stomatal closure and reduced supply of carbon dioxide ( $\mathrm{Li}$ et al. 2008). Furthermore, membrane disorganization and disturbance of nutrient balance may be induced by salt stress (Hasegawa et al. 2000).

\section{Variation between species and individual trees in each species}

Figure 3 shows the stem growth rate for nine species. The result from the ANOVA statistical test indicated that average stem growth rate was significantly different between species $(F(8,243)=7.063, p$-value $=0.00$, < $0.05)$. A relatively highest growth was measured on $S$. alba $\left(1.65 \pm 0.69 \mathrm{~mm} \mathrm{month}^{-1}\right)$ and a relatively lowest growth on $R$. stylosa, X. moluccensis, A. marina, C. tagal, measured at $0.82 \pm 0.16,0.82 \pm 0.18,0.85 \pm 0.18,0.88 \pm$ 
$0.28 \mathrm{~mm}$ month $^{-1}$ respectively. A relatively medium growth rate was measured on $R$. apiculata, B. parviflora, $B$. gymnorrhiza, $R$. mucronata, measured at $1.19 \pm 0.16,1.22$ $\pm 0.69,1.25 \pm 0.49,1.31 \pm 0.22 \mathrm{~mm} \mathrm{month}^{-1}$, respectively.

When the growth rates were expressed as a percentage of the initial girth of each tagged tree (Table 2), there was apparently higher stem growth rates on tagged trees of $B$. gymnorrhiza, $C$. tagal and $R$. mucronata with an initial girth of more than $50 \mathrm{~cm}$ compared to trees with an initial girth of less than $50 \mathrm{~cm}$. Conversely, there was a relatively slower growth rate on tagged trees of $R$. apiculata and $S$. alba with an original girth of more than $50 \mathrm{~cm}$ compared to trees with an initial girth of less than $50 \mathrm{~cm}$. As can be seen from results of ANOVA Test in Table 1, stem growth rates were significantly different by individual trees in six species tested.

Results from this study confirmed that the nine mangrove species had different growth rate, and the growth rate recorded in this study is different compared to those conducted elsewhere. For example, the annual diameter increment of $R$. apiculata was $0.32 \mathrm{~cm}^{\text {year }}{ }^{-1}$ in mature mangrove forests in Malaysia (Putz and Chan 1986) and $0.25 \mathrm{~cm}$ year $^{-1}$ in the mangrove forests in Micronesia (Devoe and Cole 1998) which were lower than the average growth rate by this species in this study $(0.45 \mathrm{~cm} /$ year $)$. For B. gymnorrhiza, the annual growth increments were reported $0.35 \mathrm{~cm} \mathrm{year}^{-1}$ in Micronesia which were relatively lower compared to the growth rate of this species in this study $\left(0.48 \mathrm{~cm}\right.$ year $\left.^{-1}\right)$. The annual diameter increments of $S$. alba were reported $0.49 \mathrm{~cm} \mathrm{year}^{-1}$ in the mangrove forests in Micronesia (Devoe and Cole 1998) which were relatively lower compared to the growth rates of these species measured in this study $\left(0.60 \mathrm{~cm}^{\text {year }}{ }^{-1}\right)$. Differences in growth rate of similar species from different places explained the important role of local environment and climatic condition to growth of mangrove species.

In this study, large trees of B. gymnorrhiza, C. tagal, $R$. mucronata grew faster than small trees. The case for trees of B. gymnorrhiza and $R$. mucronata might explain that trees of these species remained at vigorous growth. Meanwhile, the case for trees of $C$. tagal might be different. Small trees of this species were found dominant at Site 2 and 3 where salinity is usually higher, and that trees are growing stunted at this condition. Sample of large trees of this species was found at Site 11 where soil water salinity was lower. Thus, in the case of $C$. tagal, differences in growth rate between small and large trees were due to primarily soil water salinity.

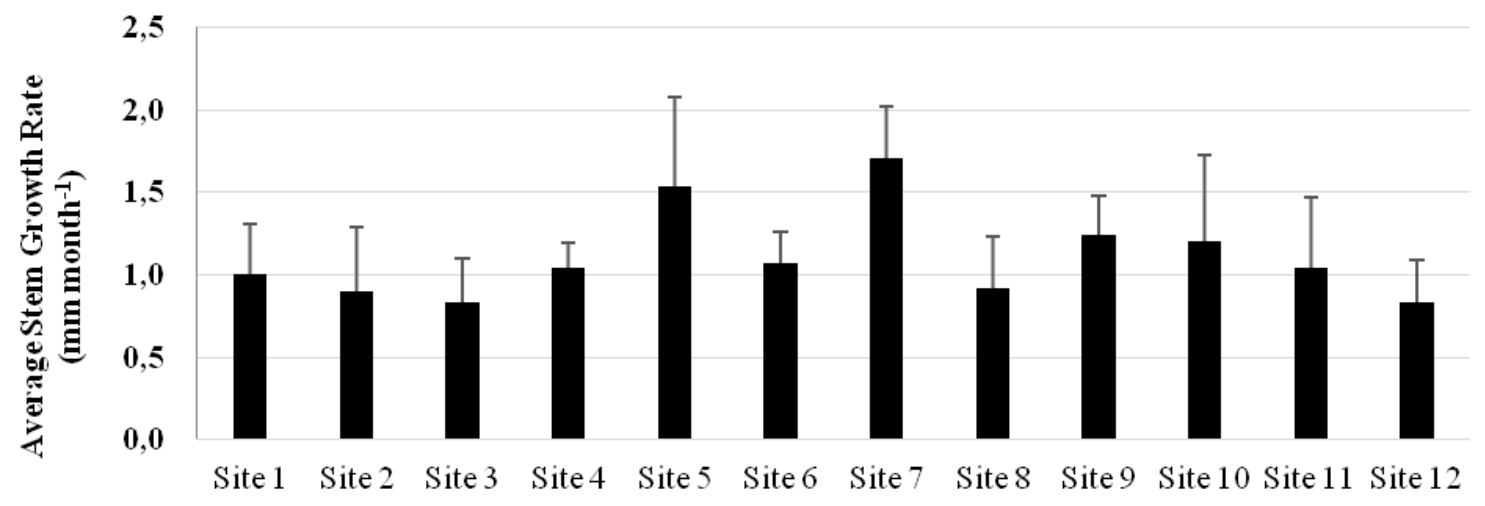

Figure 2. Average stem growth rates of tagged trees at various sites over 59 months; error bars are standard deviations representing variability over 59 months

Table 2. Average stem growth rate (girth increment and as percentage of initial girth measured for nine species over 59 months); error bars (Standard Deviations) represented variability over 59 months; n represented number of tagged tree; ANOVA Test of average stem growth rates of individual trees in six species over 59 months observation

\begin{tabular}{llcl}
\hline \multicolumn{1}{c}{ Species } & \multicolumn{2}{c}{$\begin{array}{c}\text { Stem growth rate as percent initial girth in } \\
\mathbf{~ m m} / \mathbf{m o n t h}(\mathbf{m e a n} \pm \mathbf{S D})\end{array}$} & $\begin{array}{c}\text { ANOVA test of the differences in growth } \\
\text { rates by individual trees in each species }\end{array}$ \\
\cline { 2 - 3 } & \multicolumn{1}{c|}{$<\mathbf{5 0} \mathbf{~ c m}$} & $0.85 \pm 0.58(\mathrm{n}=7)$ & $(F=24.894, p \text {-value }<0.05)^{*}$ \\
A. marina & - & $1.33 \pm 1.05(\mathrm{n}=5)$ & $(F=35.553, p \text {-value }<0.05)^{*}$ \\
B. gymnorrhiza & $0.83 \pm 0.55(\mathrm{n}=1)$ & - & - \\
B. parviflora & $1.22 \pm 0.81(\mathrm{n}=1)$ & $1.21 \pm 0.76(\mathrm{n}=2)$ & $(F=113.795, p \text {-value }<0.05)^{*}$ \\
C. tagal & $0.80 \pm 0.59(\mathrm{n}=8)$ & $0.96 \pm 0.58(\mathrm{n}=5)$ & $(F=21.020, p \text {-value }<0.05)^{*}$ \\
R. apiculata & $1.37 \pm 0.59(\mathrm{n}=6)$ & $0.69 \pm 0.59(\mathrm{n}=1)$ & $(F=16.108, p \text {-value }<0.05)^{*}$ \\
R. mucronata & $0.47 \pm 0.56(\mathrm{n}=4)$ & $0.85 \pm 0.48(\mathrm{n}=2)$ & - \\
R. stylosa & - & $1.60 \pm 0.92(\mathrm{n}=3)$ & $(F=30.857, p \text {-value }<0.05)^{*}$ \\
S. alba & $1.73 \pm 0.89(\mathrm{n}=2)$ & $0.82 \pm 0.41(\mathrm{n}=1)$ & - \\
X. moluccensis & - & &
\end{tabular}

Note: *: significant difference 


\section{Seasonal variation}

Figure 4 shows average stem growth rates of 48 tagged trees selected from 12 different sites. This figure shows that average stem growth rate started to increase in August or October over a year. This trend reached a maximum value in February at different levels with the highest level of 2.24 mm month ${ }^{-1}$ in February 2001 and the lowest level of 1.33 $\mathrm{mm}$ month $^{-1}$ in February 2016. From February, stem growth rate decreased and reached minimum value around August and October at different levels ranging from 0.53 mm month ${ }^{-1}$ in August 2015 to $0.74 \mathrm{~mm} \mathrm{month}^{-1}$ in August 2014. Between April 2015 and February 2016 there was abnormality in stem growth rate. During this period rates of average stem growth rates were apparently low.

A seasonal pattern in stem growth rates is very clear from data in Figure 4 and this is supported by the result from regression analyses, multiple and simple analyses. When two variables of rainfall and temperature were involved in the analysis the result confirmed that the regression model was significant ( $p$-value $<0.05)$. Similar result was confirmed from simple regression with single variable of rainfall and temperature ( $p$-value $<0.05$ ). Figure 5 shows relationship between rainfall and stem growth rate. It is clear from this figure that rainfall positively correlated with stem growth. On the contrary, temperature negatively correlated with stem growth as shown in Figure 6.

Previous studies indicated that growth rate in mangroves is seasonal (e.g. Jintana et al. 1985; Day 1990; Krauss et al. 2006). Field measurements indicated that growth rate is seasonal in study sites and this correlates positively with rainfall and negatively with temperature. Duke et al. (1981) also found that the growth of the tropical mangrove trees Diospyros was related to rainfall, producing $0.272 \mathrm{~mm}^{2}$ growth increment per millimeter rain. This positive correlation between rainfall and growth rate was reported for Bruguiera and Rhizophora species in Thailand (Jintana et al. 1985) and the mangroves in Laguna de Terminos, Mexico (Day 1990).

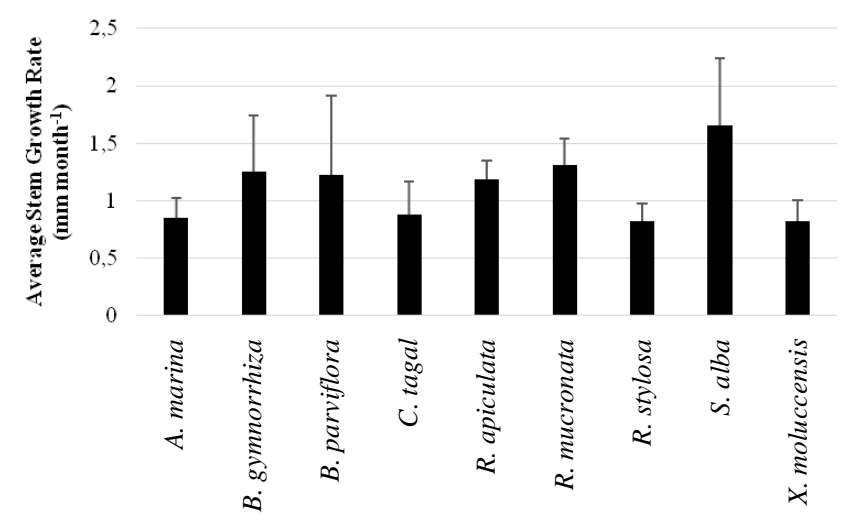

Figure 3. Average stem growth rate of nine species over 59 months; error bars (Standard Deviations) represented variability over 59 months

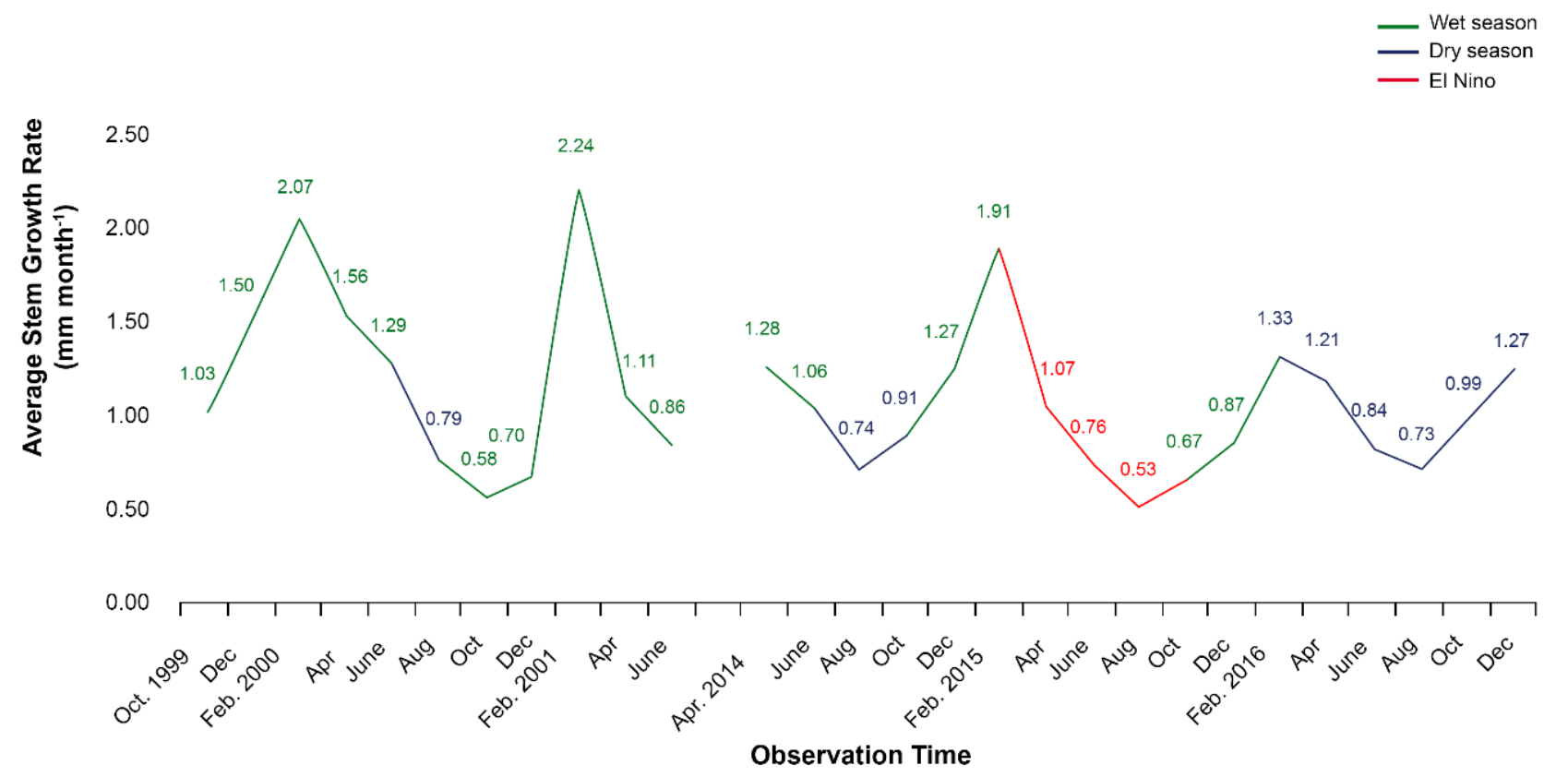

Figure 4. Temporal average stem growth rate over 59 months; wet season is started when rainfalls of three consecutive ten days periods are less than $50 \mathrm{~mm}$ and wet season when there are more than $50 \mathrm{~mm}$; El Nino is based on El Nino Index 
The effect of rainfall and temperature on intertidal environment where mangroves grew may be related to two factors; water availability and soil water salinity. Between these two factors, soil water salinity is assigned as the major seasonal variable causing wood anatomical changes and hence growth rings (Robert et al. 2009). In addition, Robert et al. (2011) in their study of the mangrove forest of Gazi Bay at the Kenyan coast confirmed that climatic conditions that result in a range of soil water salinity experienced over the year were a prerequisite for the formation of growth rings. The low growth rate that was recorded between April 2015 and February 2016 corresponds with a dry season. The effect of the 2015/2016 El Nino-Southern Oscillation (ENSO) resulted in reduced rainfall in the region with only $450.3 \mathrm{~mm}$ rainfall in total for eight months from March to October 2015. The most severe drought condition lasted for four months from July to October 2015 with only $13 \mathrm{~mm}$ of rainfall in total.

Although, the volume of rainfall returned to normal by November 2015 measured at $337 \mathrm{~mm} \mathrm{month}^{-1}$, the effect of the drought on low growth rate continued until February 2016. Drexler and Ewel (2001) studied the effect of the 1997-1998 ENSO related drought on hydrology and salinity in a Micronesian Wetland Complex. They found that mean salinity during low tide was approximately twice as high during the drought, and short-term climate perturbations such as ENSO can disrupt important coastal processes. Over repeated drought cycles, such perturbations have the potential to affect the structure and function of mangrove forests. The effect of drought on mangroves can be related to the decrease of carbon assimilation rate (Sobrado 1999), decrease of net photosynthetic rate and low water use efficiency (Sobrado 2006).

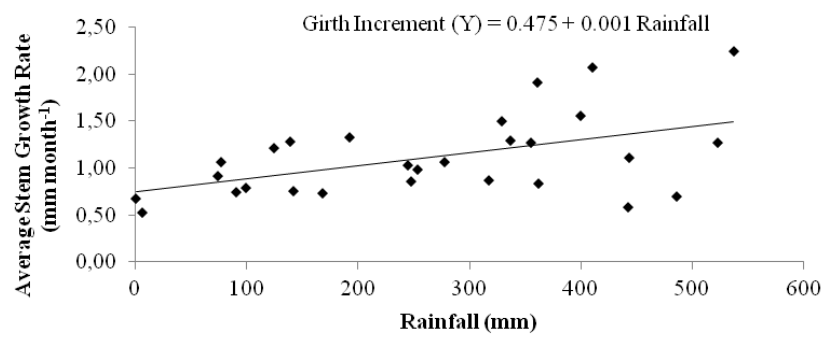

Figure 5. Relation between rainfall and stem growth rate, $r$ value $=0.50$

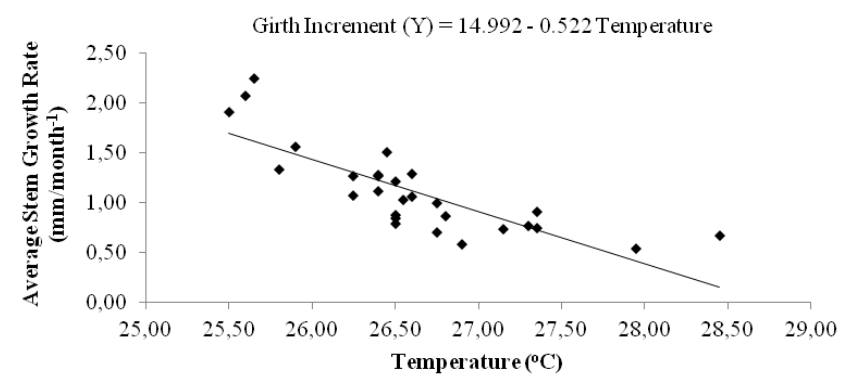

Figure 6. Relation between temperature and stem growth rate, $r$ value $=-0.80$
In conclusion, stem growth rates in mangrove trees growing at different habitats varied considerably, and the factor of soil water salinity seemed to be the major cause of this variation at high intertidal environment. The higher stem growth rate was measured on mangrove trees growing at low intertidal environment with low to medium soil water salinity and higher tidal inundation frequency. Soil water salinity and growth rates relationship may not be significant in the existence of micro-topography such as river levee and transgressed bedrock coast, and in the case at the middle intertidal environment where trees of $B$. gymnorrhiza and $R$. apiculata were dominant in the canopy. The stem growth rates were significantly different between the nine species observed with a relatively higher growth rate on $S$. alba, a medium growth rate on $R$. apiculata, B. parviflora, B. gymnorrhiza, R. mucronata, and a low growth rate on $R$. stylosa, X. moluccensis, A. marina, $C$. tagal. Growth rates on trees with an original girth of more than $50 \mathrm{~cm}$ were higher on B. gymnorrhiza, $C$. tagal and $R$. mucronata, but these were higher on trees with an original girth of less than $50 \mathrm{~cm}$ on $R$. apiculata and $S$. alba. Growth rate patterns in observed mangroves were seasonal, and this pattern correlated positively to rainfall and negatively to temperature. The effect of the 2015-2016 El Nino on reduced growth rates was significant on mangroves in the study site.

\section{ACKNOWLEDGMENTS}

This research was supported in part by Ausaid-ADS Program. It is a pleasure to thank Brama Djabar for site map preparation, Kelola's staffs, Im and Mubin for field assistance, Prof. Eugene Moll, Dr. David Lamb, Dr. Jim Davie, Dr. Norm Duke for supervision of the early work. I also thank Kate Night for helpful edits and comments.

\section{REFERENCES}

Clough BF. 1979. Mangrove ecosystem in Australia: structure, function and management. Proc Aust Natl Mangrove Workshop. Australian Institute of Marine Science, Cape Ferguson, 18-20 April 1979.

Day RH. 1990. Growth rates of three species of mangroves bordering Laguna de Terminos, Campeche, Mexico. [Thessis]. The University of Texas, Texas.

Davie J, Djamaluddin R. 1996. The sustainable use and conservation of the mangrove ecosystems of Bunaken National Park. Associates in Rural Development for Office of Agro-Enterprise and Environment, USAID, Jakarta. [Indonesia]

Devoe NN, Cole TG. 1998. Growth and yield in mangrove forests of the Federal States of Micronesia. For Ecol Manag 103: 33-48.

Ding Hou. 1958. Rhizophoraceae. Flora Malesiana I(5):429-93.

Djamaluddin R. 2004. The dynamics of mangrove forest in relation to dieback and human use in Bunaken National Park, North Sulawesi, Indonesia. [Dissertation]. University of Queensland, Brisbane.

Djamaluddin R. 2018. The mangrove flora and their physical habitat characteristics in Bunaken National Park, North Sulawesi, Indonesia. Biodiversitas 19(4):1303-1312. [Indonesia]

Drexler JZ, Ewel KC. 2001. Effect of the 1997-1998 ENSO-related drought on hydrology and salinity in a Micronesian Wetland Complex. Estuaries 24(3):347-356.

Duke NC. 1992. Mangrove floristic and biogeography. In: Robertson AI, Alongi DM (eds) Coastal and Estuarine Studies. American Geophysical Union, Washington. 
Duke NC, Birch WR, Williams WT. 1981. Growth rings and rainfall correlations in a mangrove tree of the genus Diospyros (Ebenaceae). Aust J Bot 29:135-142.

Giesen W, Wulffraat S, Zieren M, Scholten L. 2006. Mangrove guide book for Southeast Asia. FAO and Wetlands International.

Gill AM. 1971. Endogenous control of growth ring development in Avicennia. For Sci 17:462-465.

Hamilton SE, Casey D. 2016. Creation of a high spatiotemporal resolution global database of continuous mangrove forest cover for the $21 \mathrm{st}$ century (CGMFC-21). Glob Ecol Biogeogr 25(6): 729-738.

Hasegawa PM, Bressan RA, Zhu JK, Bohnert HJ. 2000. Plant cellular and molecular responses to high salinity. Ann Rev Plant Phys 51:463-499.

Jintana V, Komiyama A, Moriya H, Ogino K. 1985. Forest ecological studies of mangrove ecosystem in Ranong, Southern Thailand-4. Diameter growth measurement by dendrometry. In: Studies on the mangrove ecosystem. Nodai Research Institute (eds) Tokyo University of Agriculture, Japan.

Kathiresan K, Bingham BL. 2001. Biology of mangrove and mangrove ecosystem. Adv Mar Biol 40:81-251.

Krauss KW, Keeland BD, Allen JA, Ewell KC, Johnson DJ. 2006. Effects of season, rainfall, and hydrogeomorphic setting on mangrove tree growth in Micronesia. Biotropica 39(2):161-170.

Li N, Chen S, Zhou Z, Xy, Li C, Shao J, Wang R, Fritz E, Huttermann A, Polle A. 2008. Effect of $\mathrm{NaCl}$ on photosynthesis, salt accumulation and ion compartmentation in two mangrove species, Kandelia candel and Bruguiera gymnorrhiza. Aquat Bot 88:303-310.

Maxwell GS. 2015. Gaps in mangrove science. ISME/GLOMIS 13(5):18 38 .

Menezes M, Berger U, Worbes M. 2003. Annual growth rings and longterm growth patterns of mangrove trees from the Bragança peninsula, North Brazil. Wetl Ecol Manag 11:33-242.

Nazim K, Ahmed M, Shaukat SS, Khani MU, Ali QM. 2013. Age and growth rate estimation of grey mangrove Avicennia Marina (Forsk,) Vier from Pakistan. Pak J Bot 45(2): 535-542.

Noor T, Batool N, Mazhar R, Ilyas N. 2015. Effects of siltation, temperature and salinity on mangrove plants. Eur Acad Res 2 (11): 14172-14179.
Noor YR, Khazali M, Suryadiputra INN. 2006. Mangrove introduction guide. Ditjen PPHKA-Wetland International, Bogor. [Indonesia]

Putz FE, Chan HT. 1986. Tree growth, dynamics, and productivity in a mature mangrove forest in Malaysia. For Ecol Manag 17:211-230.

Rajkaran A, Adams JB. 2008. The effect of sediment conditions on the growth rate of mangroves. S Afr J Bot 74(2): 375-376.

Robert EMR, Schmitz N, Okello JA, Boeren I, Beechman H, Koedam N. 2011. Mangrove growth rings: fact or fiction. Trees 25:49-58.

Robert EMR, Schmitz N, Kirauni HA, Koedam N. 2009. Salinity fluctuations in the mangrove forest of Gazi Bay, Kenya: lessons to take for future research. Nat Fauna 24: 89-95.

Sobrado MA. 1999. Drought effects on photosynthesis of the mangrove, Avicennia germinans, under contrasting salinities. Trees 13(3): 125130.

Sobrado MA. 2006. Deferential gas exchange responses to salinity and drought in the mangrove tree Avicennia germinans (Avicenniaceae). Int J Trop Biol 54(2):371-375.

Spalding MD, Blasco F, Field CD. 1997. World Mangrove Atlas. Int Soc Mangrove Ecosyst, Okinawa.

Srikanth S, Lum SKY, and Chen Z. 2015. Mangrove root: adaptations and ecological importance. Tress 30(2): 451-465.

Suarez N, Sobrado MA, Medina E. 1998. Salinity effects on the leaf water relations components and ion accumulation patterns in Avicennia germinans (L.) seedlings. Oecologia 114:299-304.

Thom BG. 1982. Mangrove ecology-a geomorphological perspective. In: Clough BF (eds) Mangrove ecosystem in Australia: structure, function, and management. AIMS with ANU Press, Canberra.

Tomlinson PB. 1986. The botany of mangroves. Cambridge University Press, New York.

Valiela I, Bowen JL, York YK. 2001. Mangrove forests: one of the world's threatened major tropical environments. BioScience 51(10): 807-815.

Verheyden A, Kairo JT, Beeckman H, Koedam N. 2004. Growth rings, growth ring formation, and age of mangrove Rhizophora mucronata. Ann Bot 94: 59-66. 